\title{
Theoretical-Experimental Photophysical Investigations of the Solvent Effect on the Properties of Green- and Blue-Light-Emitting Quinoline Derivatives
}

\author{
Giovanny Carvalho dos $\operatorname{Santos}^{1} \cdot$ Roberta Oliveira Servilha ${ }^{1}$. \\ Eliézer Fernando de Oliveira ${ }^{2}$ - Francisco Carlos Lavarda ${ }^{2}$. \\ Valdecir Farias Ximenes ${ }^{1} \cdot$ Luiz Carlos da Silva-Filho $^{1}$
}

Received: 12 January 2017 / Accepted: 26 April 2017 /Published online: 11 May 2017

(C) Springer Science+Business Media New York 2017

\begin{abstract}
This paper describes the investigations on the solvatochromic effect and the photophysical properties of quinoline derivatives, compounds with potential applicability in optoelectronic devices. Using an experimental and theoretical approach, the effect of the solvent and the insertion of the phenyl, nitro, amino and dimethylamino group in the quinoline backbone were investigated. The use of Density Functional Theory (DFT) calculations provided the bases for the understanding of the energetic transitions observed in the absorption and fluorescence experiments. In general, it was observed a change in the wavelength of maximum absorption and fluorescence quantum yield of the studied compounds caused by the substituents in the quinoline core. This effect was correlated with the solvent dielectric constants.
\end{abstract}

Keywords Niobium pentachloride - Quinoline derivatives · Solvatochromic effect · DFT · Photoluminescence

\section{Introduction}

Over the last years, the Science community has turned its attention to luminescent organic and organometallic compounds which have aroused great interest due to their potential applications as organic solar cells (OSCs), biomolecular labels, organic light-emitting diodes (OLEDs), molecular probes and switches,

Luiz Carlos da Silva-Filho

lcsilva@fc.unesp.br

1 Department of Chemistry, São Paulo State University (UNESP), School of Sciences, 17033-360, Bauru, São Paulo, Brazil

2 Department of Physics, São Paulo State University (UNESP), School of Sciences, 17033-360, Bauru, São Paulo, Brazil laser dyes, and organic $\pi$-conjugated in solution-processed bulkheterojunction (BHJ) organic photovoltaic devices [1].

Molecules such as quinolines have been of great interest in the fields of organic and medicinal chemistry since there is a large number of natural products and drugs that present this heterocyclic moiety in their structure. As a result, their use has been reported in several medical applications [2, 3]. In addition, quinoline derivatives have also been used in polymer chemistry, organic electronics and optoelectronics. This is because quinoline derivatives have excellent mechanical properties, generating highly efficient materials in the electron transport [4], presenting crucial characteristics for their use in OLEDs, such as high electron mobilities, good thermal stability, high photoluminescence efficiencies and good film forming properties [5]. Therefore, a significant improvement in luminescence efficiency and brightness in OLEDs is observed when molecules contain quinolines [6].

Predominant advantages can be attributed in the competitive nature of small molecules in relation to the polymeric materials, including well-defined molecular structures, good flexibility, light weight, low cost, simple synthesis and fabrication-processing, an easier purification process and a better reproducibility [7].

Phenyl quinoline compounds are known to have an excellent photochemical stability even under high intensity laser irradiation [8]. We also know that a broad, intense absorption spectrum with molecules bearing the quinoline nucleus leads to a higher amount of short-circuit current density $\left(J_{s c}\right)$. In addition, there is the possibility of modulating the emission wavelength of such compounds by introducing functional groups and/or extending the conjugation around the core [8].

The donor-acceptor (D-A) concept for band gap reduction was proposed by Havinga et al. in 1992 [9]. Through simple modifications, donors and acceptors groups can be inserted in the quinoline backbone. This makes this class of molecules 
important compounds to be studied more thoroughly for future applications in the field of organic electronics that continues to evolve [10].

Yune and co-workers prepared the binder-free $\mathrm{TiO}_{2}$ colloidal pastes using quinoline backbone to produce robust photoanodes for dye-sensitized solar cells (DSSC) [11]. Bulkier heterocyclic bases as quinoline derivatives can also be tested for this purpose, but we need to know the influence of substituents in the photoproperties at the molecule. As it can be seen, substituents have a key effect on the properties of fluorophores. Thus, in this paper we report the photophysical investigation of the solvent effect on quinoline derivatives, synthesized through multicomponent reaction (MCR) among arylaldehydes, anilines and alkynes catalyzed by Niobium Pentachloride, as described recently by our research group [12]. In addition, to better understand the photophysical properties of substituted quinoline derivatives, computational simulations using the Density Functional Theory (DFT) were performed.

\section{Experimental}

\section{Materials and Instrumentation}

The complete synthesis and full spectral characterization (NMR, MS, IR and other techniques) of all studied compounds have been reported previously [12]. All reactions were performed under air atmosphere, unless otherwise specified. Acetonitrile was distilled from calcium hydride. The quinoline backbone (compound $\mathbf{1}$ ) is commercially available in SigmaAldrich. All commercially available reagents were used without further purification. The $\mathrm{NbCl}_{5}$ used was supplied by Companhia Brasileira de Metalurgia e Mineração (CBMM). Thin-layer chromatography was performed on $0.2 \mathrm{~mm}$ Merck $60 \mathrm{~F}_{254}$ silica gel aluminum sheets, which were visualized with a vanillin/methanol/water/sulfuric acid mixture, molybdate or UV-365 nm irradiation. Bruker DRX 400 spectrometer was employed for the NMR spectra $\left(\mathrm{CDCl}_{3}\right.$ solutions) using tetramethylsilane as internal reference for ${ }^{1} \mathrm{H}$ and $\mathrm{CDCl}_{3}$ as an internal reference for ${ }^{13} \mathrm{C}$. A Bruker FTIR model VERTEX 70 was used to record IR spectra (neat). HRMS analyses were recorded in a micrOTOF (Bruker), with ESI-TOF detector working on positive mode. UV-Vis absorption spectra were obtained in a SpectraMax M2 spectrophotometer (Molecular
Devices, USA) using a $1.0 \mathrm{~cm}$ light path quartz cuvette at room temperature. Fluorescence emission spectra were obtained using a Synergy2 Multi-Mode reader (BioTek, USA).

Quantum yields were analyzed by adjusting the solution absorption using the UV-Vis to ca. 0.05 at $272-388 \mathrm{~nm}$ wavelength, the output was measured using the luminescence spectrophotometer at the same wavelength and comparing it to the known 9,10-diphenylanthracene standard using Eq. 1 Quantum yield calculation using 9,10-diphenylanthracene:

$\Phi_{f}=\Phi_{s t d} x \frac{A_{s t d} F}{A F_{\text {std }}} \times \frac{n^{2}}{n_{\text {std }}^{2}}$

$\Phi$ is the fluorescence quantum yield, $\mathrm{A}$ is the absorption of the excitation wavelength, $\mathrm{F}$ is the area under the emission curve, and $n$ is the refractive index of the solvents used. Subscript std. denotes the standard. The compounds were solubilized in ethanol and the concentration maintained at about $5 \times 10^{-6} \mathrm{~mol} . \mathrm{L}^{-1}$ to follow the protocol for analysis [13].

\section{Computational Details}

All theoretical calculations were performed with GAUSSIAN09 program [14]. Ground state geometries were fully optimized by Density Functional Theory (DFT), employing the Becke three-parameter Lee - Yang - Parr exchange-correlation functional (B3LYP) [15] and the basis set functions 6-31G(d) [16]. The solvation effects were simulated by the Polarizable Continuum Model (PCM) [17, 18]. Today, there are large amounts of available functionals within the DFT theory and our option for the B3LYP is based on the fact that it has already been successfully used in other studies with quinoline derivatives [19-24]. The equilibrium geometries were confirmed by vibrational spectrum calculations since no imaginary frequencies were found.

\section{Results and Discussion}

\section{The Solvent Effect on UV-vis Absorption of Quinoline and Its Derivatives}

Firstly, to investigate the solvent effect in quinoline $\mathbf{1}$ and its derivatives 2, 3 and $\mathbf{4}$ (Fig. 1), the UV-Vis absorption of these

Fig. 1 Quinoline and derivatives<smiles>c1ccc2ncccc2c1</smiles>

1



2<smiles>Nc1ccc2nc(-c3ccccc3)cc(-c3ccccc3)c2c1</smiles>

3<smiles>CN(C)c1ccc(-c2cc(-c3ccccc3)c3cc(N)ccc3n2)cc1</smiles>

4 
Fig. 2 UV- Vis absorption of 1 in various solvents, $10^{-3} \mathrm{~mol} . \mathrm{L}^{-1}$

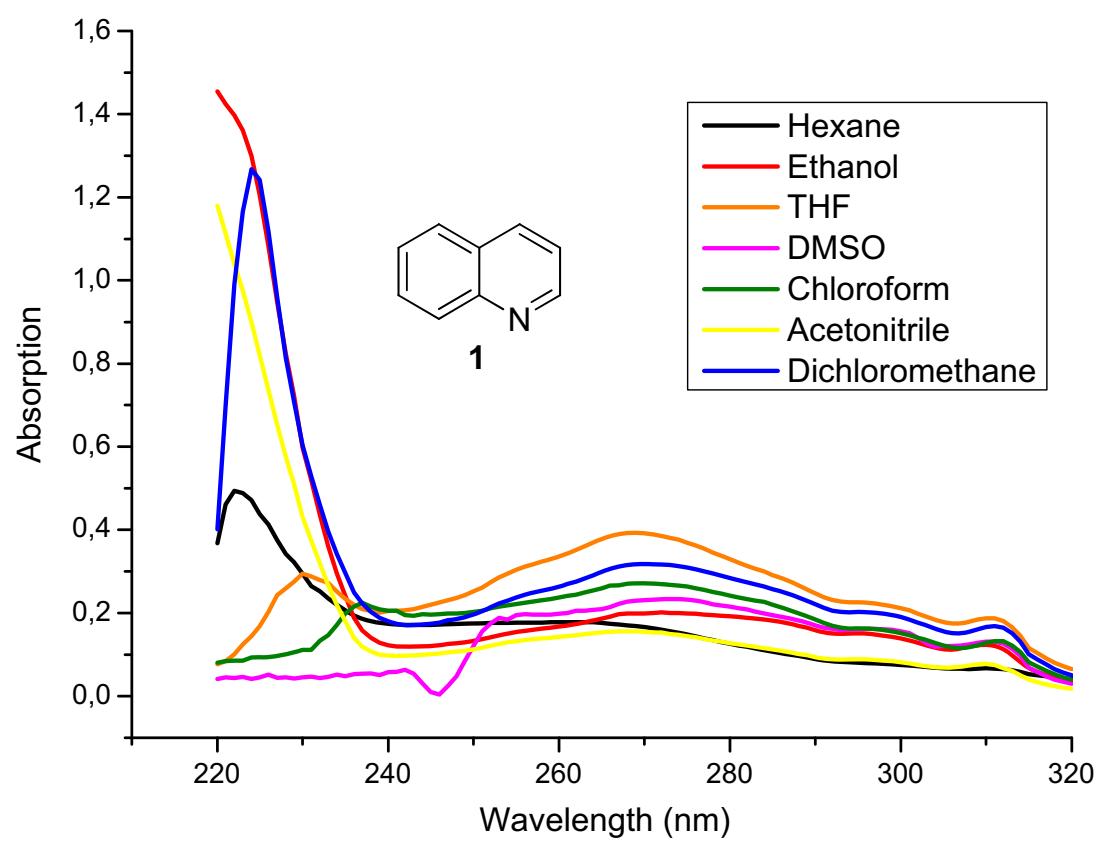

compounds was examined in various solvents with different polarities. This investigation was necessary, due the fact that electron charge distribution and the twist angle of the molecules can be explained by the solvent effect, mainly because of stacking alignment and intra-charge transfer of compounds [25]. This evaluation is important to study applications in optoelectronic devices [26].

Aiming to study the effect of the insertion of substituents in the quinoline moiety, the measurements of UV-Vis absorption in different solvents were performed to know the influence of the solvent, so it would not limit our explanation of the change in the values only in connection with the twist angle of the substituents. Figure 2 shows the UV-Vis absorption spectra of quinoline $\mathbf{1 .}$

It can be seen in Fig. 2 that the solvent altered the wavelength of maximum absorption ( $\lambda_{\max }$ ) of $\mathbf{1}$. However, by comparing only the dielectric constant values of the solvent, it was not possible to find out a pattern for the alteration in $\lambda_{\max }$. As well-established in the literature, the absorption phenomenon depends on factors that cause changes in the electronic structure of molecules such as viscosity, polarity and, therefore, solubility (Table 1) [27]. In Fig. 2, we hid the first absorption band because of a strong influence of the solvents cut off wavelength. The second and third bands have differences in shift and intensity. These bands show $\pi-\pi^{*}$ and $n-\pi^{*}$ transitions. These transitions are sensitive to solvent polarity, but in the quinoline backbone (1), they did not exhibit significant changes in the $\lambda_{\max }$.

Although it is not the only parameter responsible for changes in values, a bathochromic shift by increasing the solvent polarity indicates that the ground state tends to be better solvated by polar solvents. This behavior was observed with hexane $\left(\lambda_{\max }=261 \mathrm{~nm}\right)$ and DMSO $\left(\lambda_{\max }=274 \mathrm{~nm}\right)$, which have a difference of $13 \mathrm{~nm}$ in the $\lambda_{\max }$. It can be said that the ground state is better solvated by solvents with higher polarity in this compound [27].

Table 1 Maximum wavelength of the quinoline in some solvents ordered by dielectric increasing dielectric constant

\begin{tabular}{llllll}
\hline Solvent & Relative Polarity ${ }^{\mathrm{a}, \mathrm{b}}$ & Dipole Moment & Viscosity & Dielectric Constant & $\lambda_{\max }(\mathrm{nm})$ of 1 \\
\hline Hexane & $0,009 \mathrm{NP}$ & 0,00 & 0,33 & 1,88 & 261 \\
$\mathrm{CHCl}_{3}$ & $0,259 \mathrm{NP}$ & 1,04 & 0,57 & 4,81 & 270 \\
$\mathrm{THF}$ & $0,207 \mathrm{PA}$ & 1,75 & 0,55 & 7,5 & 269 \\
$\mathrm{DCM}$ & $0,309 \mathrm{PA}$ & 1,60 & 0,44 & 9,1 & 270 \\
$\mathrm{EtOH}$ & $0,654 \mathrm{PP}$ & 1,69 & 1,20 & 30 & 272 \\
$\mathrm{CH}_{3} \mathrm{CN}$ & $0,460 \mathrm{PA}$ & 3,92 & 0,37 & 37,5 & 268 \\
$\mathrm{DMSO}$ & $0,444 \mathrm{PA}$ & 3,96 & 2 & 46,7 & 274 \\
\hline
\end{tabular}

${ }^{a}$ Values of relative polarity were taken from the solvent displacement measurements in the absorption spectrum and were taken from the book of Christian Reichardt, Solvents and Solvent Effects in Organic Chemistry, Wiley-VCH Publishers, 3. ed., 2003.

${ }^{\mathrm{b}} \mathrm{NP}$ - Non-Polar; PA - Polar Aprotic; PP - Polar Protic 
Fig. 3 UV- Vis absorption of quinoline, nitroquinoline, aminoquinoline and dimethylamine quinoline, concentration $=10^{-3} \mathrm{~mol} . \mathrm{L}^{-1}$

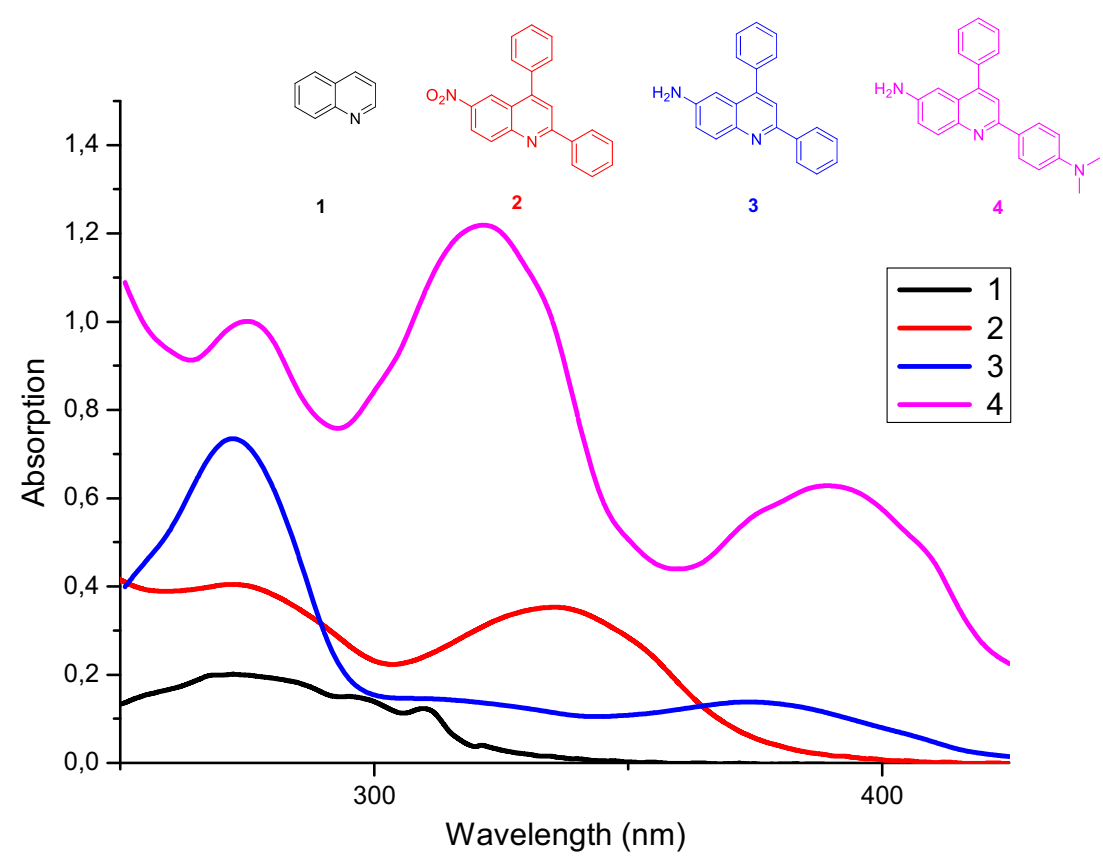

Aiming to study the effect of the insertion of the phenyl, nitro, amino and dimethylamino groups in the quinoline moiety, the measurements of UV-Vis absorption in ethanol for compounds 2, 3 and $\mathbf{4}$ were performed to observe the $\lambda_{\max }$ shift (Fig. 3).

The substituents at the quinoline backbone caused a change in the electron charge distribution and consequently a shift in the $\lambda_{\max }$. The values observed were: quinoline (1) $\lambda_{\max }=272 \mathrm{~nm}$, nitroquinoline (2) $\lambda_{\max }=335 \mathrm{~nm}$, aminoquinoline (3) $\lambda_{\max }=375 \mathrm{~nm}$ and dimethylamine quinoline (4) $\lambda_{\max }=388 \mathrm{~nm}$.
When compared to the quinoline core (1), the insertion of phenyl groups increased the electron delocalization and the consequent bathochromic shift, which could be an important property for applications of these molecules as dyes. The amino group and the dimethylamine group also caused a red shift. These groups with free electrons contribute toward the mobility of electrons in the structure. Although the phenyl substituents reduced the structural rigidity, this molecule still presented a high fluorescence quantum yield which was significantly higher compared to the parent molecule (1) [12].
Fig. 4 Fluorescence emission of quinoline and derivatives in ethanol

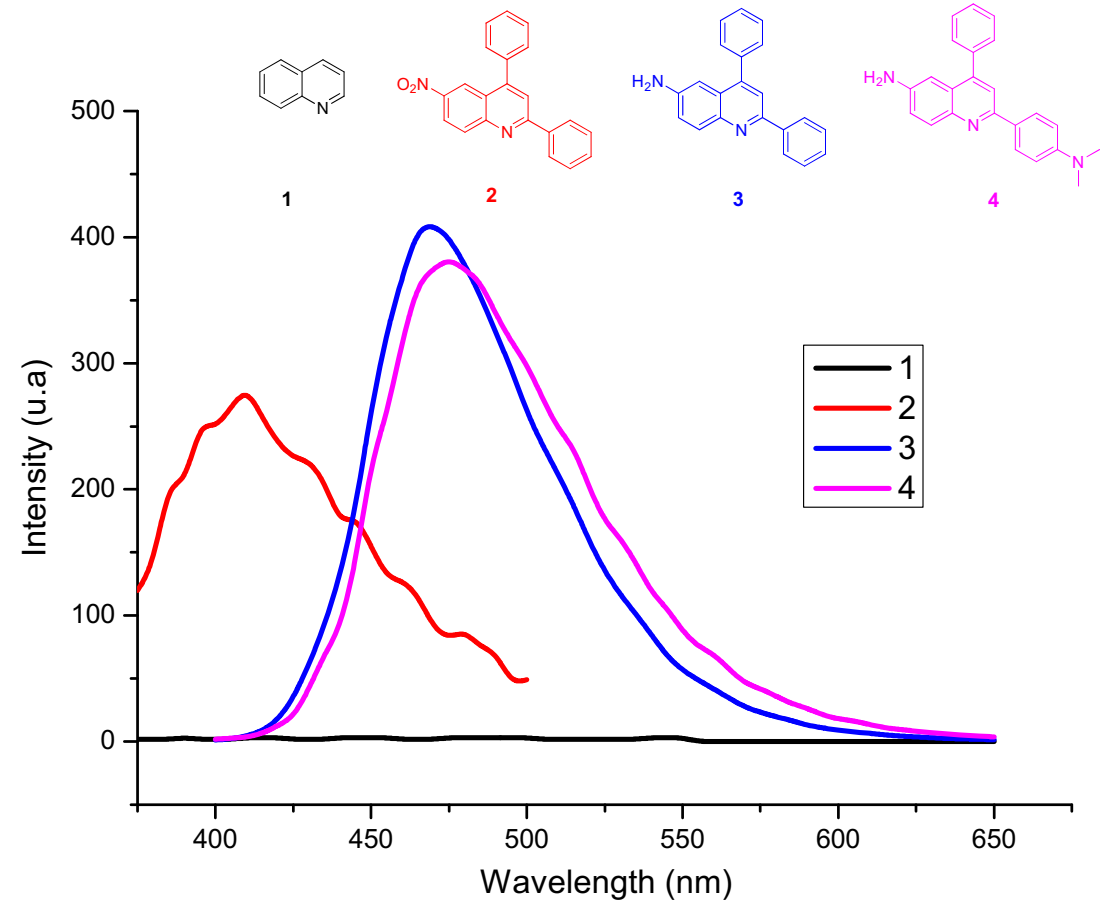


Table 2 Photophysical data of quinoline derivatives

\begin{tabular}{lllll}
\hline Compound & $\lambda_{\max }$ & $\lambda_{\mathrm{em}}$ & $\Delta \lambda \mathrm{st}$ & $\Phi \mathrm{fx}(\%)$ \\
\hline 1 & 272 & --- & --- & --- \\
2 & 335 & 410 & 75 & 0.25 \\
3 & 375 & 470 & 95 & 65.33 \\
4 & 388 & 475 & 87 & 51.70 \\
\hline
\end{tabular}

The fluorescence quantum yield and Stokes shift of nitroquinoline 2, aminoquinoline 3 and dimethyllamine quinoline 4 were also studied (Fig. 4). The results showed that quinoline backbone (1) do not exhibit fluorescence, nitroquinoline showed $0.25 \%$, aminoquinoline $65.33 \%$ and dimethylamino quinoline $57.70 \%$ of fluorescence quantum yield. This demonstrates the importance of inserting the phenyl groups to increase the conjugation of the molecule and consequent emission, but also demonstrates the key effect of the amino group on the quinoline backbone. The optical data for 1-4 in ethanol solution are summarized in Table 2.

\section{Theoretical-Experimental Solvent Effect in Quinoline Derivatives 3 and 4}

As showed in section 3.1, substituents had a key effect on the fluorescent properties of the quinoline derivatives. Hence, for a better understanding of their effects, theoretical calculations were used in this section to understand the effect of the amino (compound $\mathbf{3}$ ) and dimethylamine (compound 4) substituents. Compound 3 was chosen because it does not contain any substituent in the phenyl ring in position 2 and it is useful to know the effect of the substituent group. Compound 4 was chosen by the known effect of the dimethylamino substituent, as well as the result achieved by its absorption. This group can better contribute to the resonance structures of the quinoline
Fig. 5 a UV-Vis absorption of aminoquinoline $\mathbf{3}$ in various solvents. b Solvatochromism shown by emission of compound 3 under UV-lamp (365 nm)

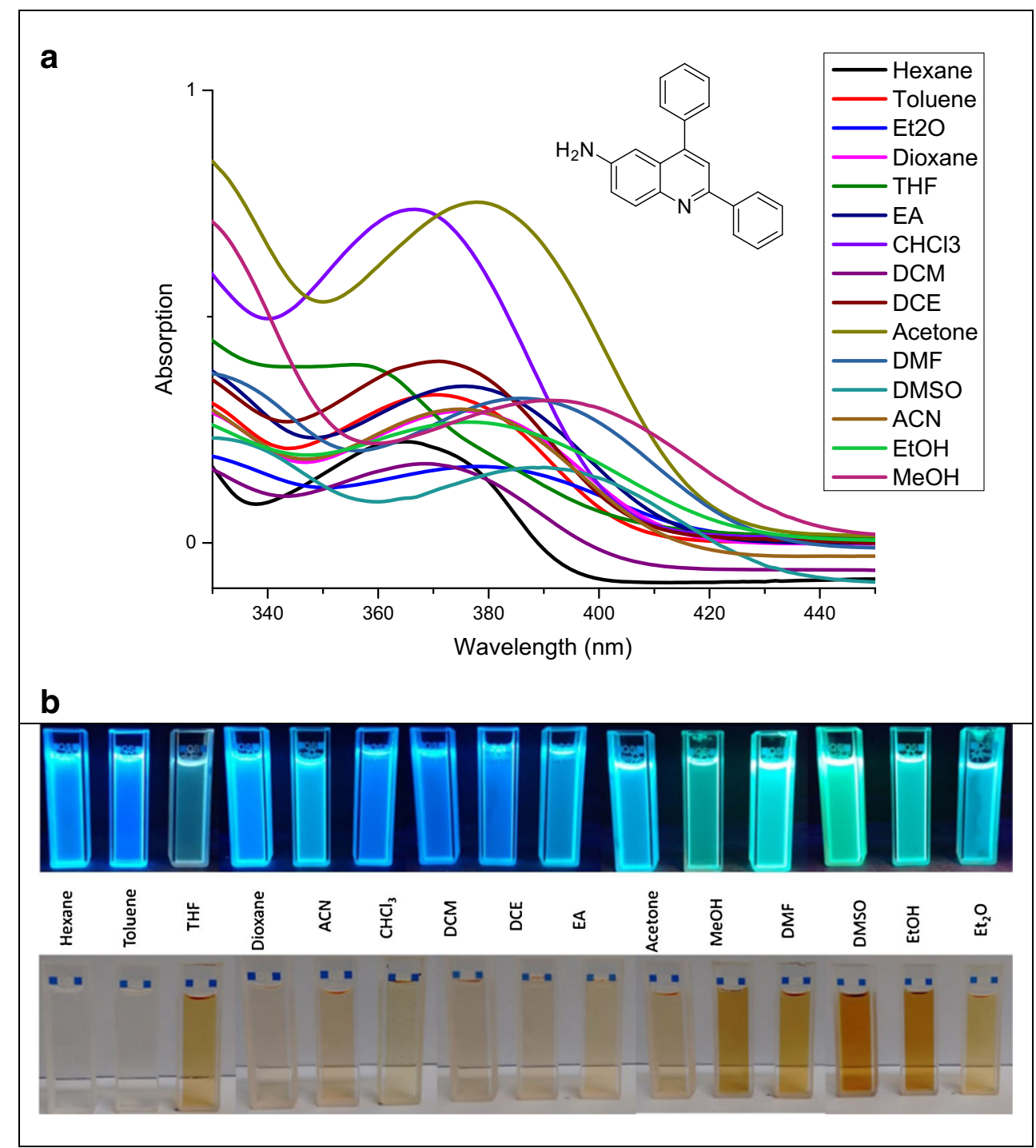


moieties upon excitation. Thus, these molecules proved to be good candidates for further photophysical study. We decided to study compound $\mathbf{4}$ as an unsymmetrical Donor-AcceptorDonor (D-A-D) type of organic small molecule, with quinoline acting as an electron-acceptor moiety.

As demonstrated in the literature, these groups contribute toward the mobility of $\pi$-electrons of the quinolines and cause different spectroscopic behavior [28]. Once these molecules could increase their absorption band through intramolecular charge transfer (ICT), and consequently encompass a larger region of the solar spectrum, then they would be able to achieve a high PCE in organic solar cells devices [29].

A variation in the intensity, shape and peak position of absorption spectra can be used to know the interactions between solute and solvent. When the compound is dissolved in different solvents and the phenomenon of change in color occurs, as well as their absorption and emission spectrum, this effect is called solvatochromism. Compounds with a large change in their permanent dipole moment upon excitation exhibit a strong solvatochromism. In compounds $\mathbf{3}$ and $\mathbf{4}$, this was observed in different intensity [30].

Compound $\mathbf{3}$ is a yellow solid and $\mathbf{4}$, a dark orange solid. They showed green to blue emission under UV-lamp (365 nm) (Figs. 5 and 6). The UV-visible absorption (Figs. 5 and 6) was recorded in different solvents at room temperature using $10^{-6} \mathrm{M}$ solutions. Compound 3 showed $\lambda_{\max }$ in the range of 355-390 nm while compound 4 was in the range of 378$403 \mathrm{~nm}$ with shoulder in the range of $474-483 \mathrm{~nm}$ in some solvents (Table 3).

Some dependence in the absorption spectra indicates a good interaction with the solvent molecule and ground state of quinoline derivatives. The solvatochromic effect is less pronounced in compound $\mathbf{3}$. Whereas, in compound $\mathbf{4}$, the non-bonding electrons on the dimethylamino group participate in the $\pi$-electron of quinoline skeleton and decrease the value of dipole moments in ground and excited states.
Fig. 6 a UV-Vis absorption of aminoquinoline 4 in various solvents. b Solvatochromism shown by emission of compound 4 under UV-lamp (365 nm)

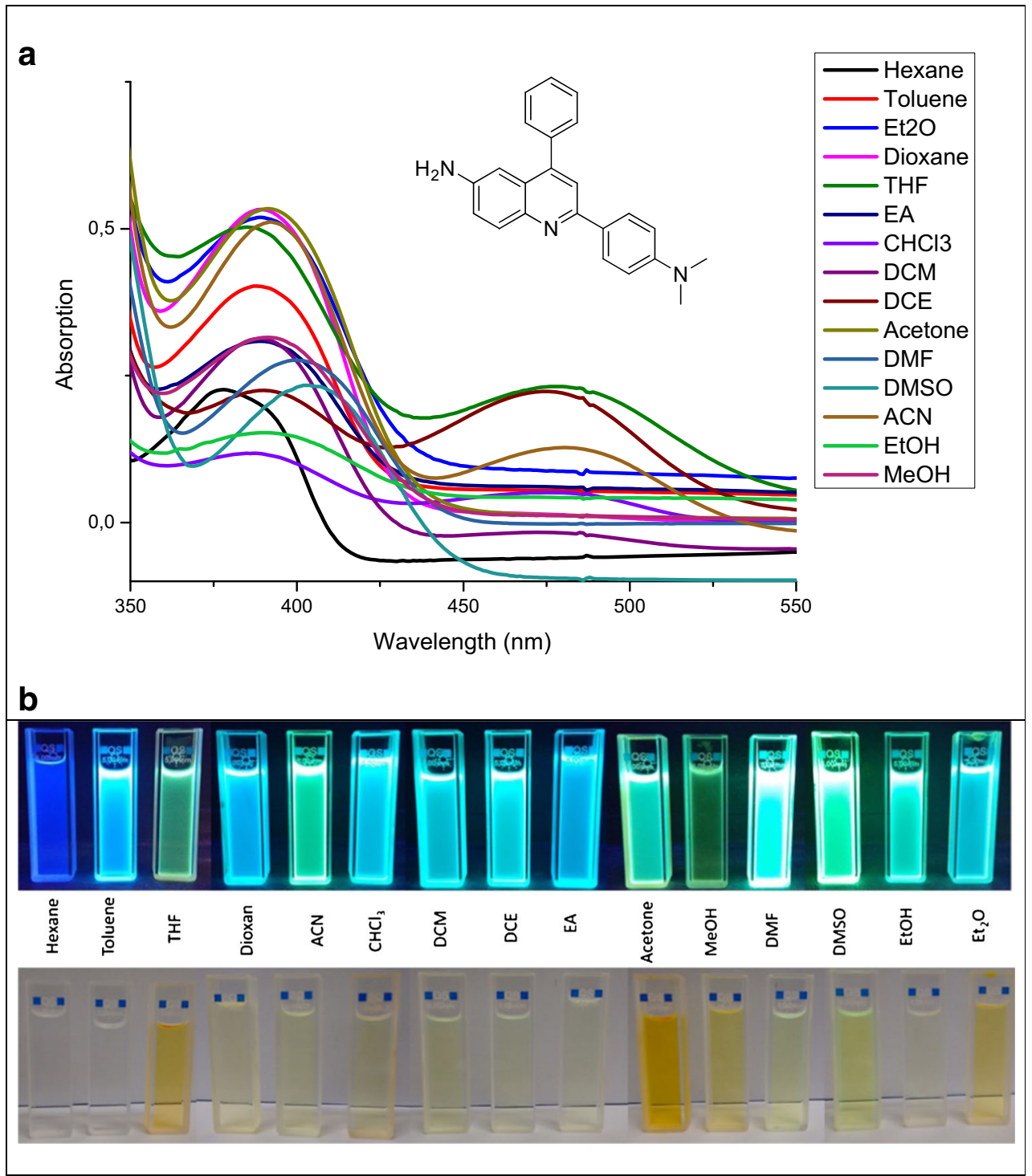


Table 3 Maximum wavelength of $\mathbf{3}$ and $\mathbf{4}$ in various solvents

\begin{tabular}{|c|c|c|c|c|c|c|c|c|}
\hline \multirow[t]{2}{*}{ Solvent } & \multirow{2}{*}{$\begin{array}{l}\text { Relative } \\
\text { polarity }{ }^{\mathrm{a}, \mathrm{b}}\end{array}$} & \multirow{2}{*}{$\begin{array}{l}\text { Dipole } \\
\text { moment }\end{array}$} & \multirow[t]{2}{*}{ Viscosity } & \multirow{2}{*}{$\begin{array}{l}\text { Dielectric } \\
\text { constant } \\
\left(20^{\circ} \mathrm{C}\right)\end{array}$} & \multicolumn{2}{|c|}{ Compound 3} & \multicolumn{2}{|c|}{ Compound 4} \\
\hline & & & & & $\begin{array}{l}\text { Exp. } \lambda_{\max } \\
(\mathrm{nm})^{\mathrm{c}}\end{array}$ & $\begin{array}{l}\text { Calc. } \lambda_{\max } \\
(\mathrm{nm})^{\mathrm{d}}\end{array}$ & $\begin{array}{l}\text { Exp. } \lambda_{\max } \\
(\mathrm{nm})^{\mathrm{c}}\end{array}$ & $\begin{array}{l}\text { Calc. } \lambda_{\max } \\
(\mathrm{nm})^{\mathrm{d}}\end{array}$ \\
\hline Hexane & $0.009 \mathrm{NP}$ & 0 & 0.31 & 1.9 & 365 & 364.18 & 378 & 401.24 \\
\hline Toluene & $0.099 \mathrm{NP}$ & 0.4 & 0.59 & 2.4 & 370 & 366.34 & 388 & 403.61 \\
\hline THF & $0.207 \mathrm{PA}$ & 1.75 & 0.55 & 7.6 & 355 & 374 & 385 (483) & 413.14 \\
\hline Dioxane & $0.164 \mathrm{NP}$ & 0.4 & 1.37 & 2.2 & 378 & 365.69 & 389 & 402.83 \\
\hline $\mathrm{ACN}$ & $0.460 \mathrm{PA}$ & 3.2 & 0.38 & 37.5 & 381 & 378.14 & $392(481)$ & 418.38 \\
\hline $\mathrm{CHCl}_{3}$ & $0.259 \mathrm{NP}$ & 1.1 & 0.57 & 4.8 & 366 & 371.53 & 387 (476) & 410.03 \\
\hline DCM & $0.309 \mathrm{PA}$ & 1.8 & 0.44 & 9.1 & 369 & 374.8 & $389(482)$ & 414.14 \\
\hline DCE & $0.327 \mathrm{PA}$ & 1.8 & 0.79 & 10.4 & 371 & 375.28 & $390(474)$ & 414.76 \\
\hline EA & $0.228 \mathrm{PA}$ & 1.7 & 0.45 & 6.0 & 375 & 372.92 & 388 & 411.79 \\
\hline Acetone & $0.355 \mathrm{PA}$ & 2.9 & 0.36 & 20.6 & 378 & 377.25 & 391 & 417.26 \\
\hline $\mathrm{MeOH}$ & $0.762 \mathrm{PP}$ & 1.7 & 0.59 & 32.6 & 374 & 378.02 & 391 & 418.24 \\
\hline DMF & $0.386 \mathrm{PA}$ & 3.8 & 0.92 & 36.7 & 386 & 376.87 & 400 & 418.44 \\
\hline DMSO & $0.444 \mathrm{PA}$ & 3.96 & 2.24 & 46.6 & 390 & 377.09 & 403 & 418.76 \\
\hline $\mathrm{EtOH}$ & $0.654 \mathrm{PP}$ & 1.7 & 1.1 & 22.4 & 375 & 377.61 & 388 & 417.71 \\
\hline $\mathrm{Et}_{2} \mathrm{O}$ & $0.117 \mathrm{NP}$ & 1.3 & 0.24 & 4.3 & 378 & 370.85 & 389 & 409.17 \\
\hline
\end{tabular}

${ }^{a}$ Values of relative polarity were taken from the solvent displacement measurements in the absorption spectrum and were taken from the book of Christian Reichardt, Solvents and Solvent Effects in Organic Chemistry, Wiley-VCH Publishers, 3. ed., 2003.

${ }^{\mathrm{b}} \mathrm{NP}$ - Non-Polar; PA - Polar Aprotic; PP - Polar Protic

${ }^{\mathrm{c}}$ Experimental values

${ }^{\mathrm{d}}$ Theoretical values

The amine and the dimethylamine group act as donator units and the quinoline backbone act as an acceptor building unit, making this an asymmetric D-A-D system. The extended absorption via $n-\pi^{*}$ intramolecular D-A-D charge transfer is a possible explanation for the shoulder ranging from 473 to $483 \mathrm{~nm}$. Compound 4 (Fig. 5) shows intramolecular charge transfer (ICT) observed in solvents THF, $\mathrm{ACN}, \mathrm{CHCl}_{3}, \mathrm{DCM}$ and DCE. This effect that the chlorinated solvents $\mathrm{CHCl}_{3}$, DCM and DCE cause happens because they best solvate in the excited state. Chlorine, which is strongly electronegative, has an interaction with the positive charges formed after the excitation of the molecule in the dimethylamine group. THF and ACN also stabilize the positive charge of the molecule. The fluorescence of these dyes in most solvents is so intensive that it is visible to naked eyes in the irradiation under normal daylight.

In order to evaluate theoretically and experimentally the solvent-dependent electronic structures in the quinolines and correlate the results, computations were performed using DFT/ PCM/B3LYP/6-31G(d), as described in Section 2.3. The experimental and theoretical results of the $\lambda_{\max }$ were described in Table 3.

The geometries of the optimized structures in vacuum of $\mathbf{3}$ and $\mathbf{4}$ are depicted in Fig. 7. As it can be seen, the main quinoline structure is planar with the attached benzenes a little twisted. Both, the lowest unoccupied and the highest occupied molecular orbitals (LUMO and HOMO, respectively), are delocalized through the molecule, indicating a good overlap between HOMO and LUMO, which favor the optical transitions between ground and excited states.

In HOMO orbitals the $\pi$-electrons are able to delocalize over the entire quinoline backbone, including amine group and phenyl group at position 2 (terminal substituents). In LUMO orbital the $\pi$-electrons are delocalized extensively over whole $\pi$-conjugated systems, including the phenyl group at position 4. This delocalization is important to lower the HOMO-LUMO gap, as it can be seen in Fig. 7 and in Tables 4 and 5 where all the computational results are summarized.

The comparative increase and decrease in the energy of the highest occupied molecular orbital (HOMO's) and lowest unoccupied molecular orbitals (LUMO's) give a qualitative idea of the excitation properties. Lower LUMO and higher HOMO levels were observed.

On the basis of the reduction potentials, the lowest unoccupied molecular orbital (LUMO) energy levels of molecule 3 were calculated to be in the range of -1.37 to $-1.60 \mathrm{eV}$ and of molecule 4 in the range of -1.14 to -1.47 . These results prove that these molecules have high electron-accepting ability. When compared to tris(8-hydroxyquinolinate)-aluminium (Alq3) $(-2.3 \mathrm{~V})$, which is one of the most widely used structures in electron-transporting materials, the LUMO energy 
Fig. 7 Optimized geometry in vacuum of (a) 3 and (b) 4 by DFT/B3LYP/6-31G(d). It is presented a top view (left) and the HOMO (middle) and LUMO (right) orbitals
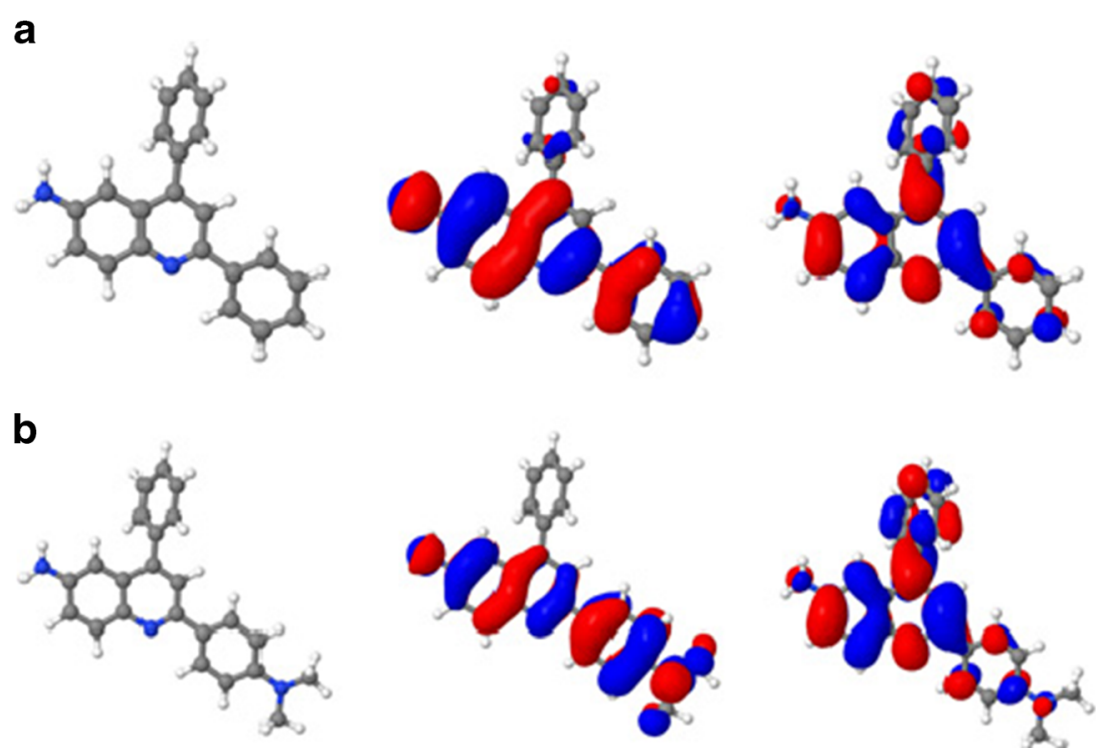

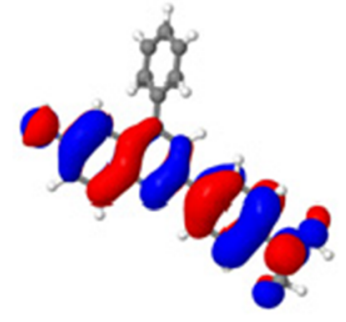

levels of $\mathbf{3}$ and $\mathbf{4}$ shifted positively [31]. The HOMO values of 3 were calculated to be in the range of -5.24 to $-5.39 \mathrm{eV}$, and of 4 in the range of -4.68 to $-4.91 \mathrm{eV}$. Bandgap energy is an essential tool for constructing optical devices. The energy gap was calculated to be in the range of 3.78 to $3.86 \mathrm{eV}$ for $\mathbf{3}$ and 3.43 to $3.53 \mathrm{eV}$ for 4 [31].

In molecules $\mathbf{3}$ and $\mathbf{4}$, a similar behavior is noted, in which the solvents with the highest dielectric constant lead to a lower energy of HOMO, LUMO and band gap. Another fact to be emphasized is that the HOMO energies of molecule $\mathbf{4}$ are higher than molecule 3; this is due to the dimethylamino group, which is a strong electron donor and tends to destabilize the orbitals energies. Hence, dimethylamine groups can contribute to the resonance structures of the quinolines backbone upon excitation. Therefore, the contribution of the positive charge on the quinoline amine group, in the resonance structures of compound $\mathbf{4}$ spectrum appears in lower energies as compared to that of $\mathbf{3}$ in the same media.

The aromaticity of the dye may sometimes be strongly affected by changes in the dihedral angles and it is noted that the difference between calculated and experimental values becomes larger as seen for azobenzene, hydrazine and cationic dyes in a study reported by Guillaument and Nakamura [32, 33]. It is inferred that the dye adopts different conformations with various solvents, which is also supported by results from quantum chemical calculations.

Table 4 Theoretical results of Compound 3 from DFT/PCM/B3LYP/6-31G(d)

\begin{tabular}{|c|c|c|c|c|c|c|c|c|c|c|c|}
\hline solvent & Dielectric constant & $\theta 1\left(^{\circ}\right)$ & dif vacuo & $\theta 2\left(^{\circ}\right)$ & dif vacuo & $\theta 3\left(^{\circ}\right)$ & dif vacuo & HOMO (eV) & LUMO (eV) & $\mathrm{GAP}(\mathrm{eV})$ & $\lambda_{\max }(\mathrm{nm})$ \\
\hline vacuo & --- & 29.169 & --- & 127.755 & --- & 17.830 & --- & -5.240 & -1.375 & 3.865 & 358.98 \\
\hline Hexane & 1.9 & 28.939 & -0.229 & 127.858 & 0.103 & 18.340 & 0.510 & -5.284 & -1.442 & 3.841 & 364.18 \\
\hline Toluene & 2.4 & 28.850 & -0.318 & 127.932 & 0.177 & 18.612 & 0.782 & -5.300 & -1.466 & 3.833 & 366.34 \\
\hline THF & 7.6 & 28.560 & -0.608 & 128.388 & 0.633 & 20.199 & 2.369 & -5.359 & -1.554 & 3.804 & 374 \\
\hline Dioxane & 2.2 & 28.878 & -0.291 & 127.907 & 0.152 & 18.522 & 0.691 & -5.295 & -1.459 & 3.835 & 365.69 \\
\hline $\mathrm{ACN}$ & 37.5 & 28.477 & -0.692 & 128.761 & 1.006 & 20.861 & 3.030 & -5.391 & -1.602 & 3.788 & 378.14 \\
\hline $\mathrm{CHCl}_{3}$ & 4.8 & 28.621 & -0.547 & 128.210 & 0.455 & 19.703 & 1.873 & -5.340 & -1.525 & 3.814 & 371.53 \\
\hline DCM & 9.1 & 28.544 & -0.625 & 128.452 & 0.697 & 20.340 & 2.509 & -5.365 & -1.563 & 3.801 & 374.8 \\
\hline DCE & 10.4 & 28.534 & -0.634 & 128.492 & 0.737 & 20.421 & 2.591 & -5.369 & -1.569 & 3.800 & 375.28 \\
\hline Ethyl acetate & 6.0 & 28.584 & -0.585 & 128.307 & 0.552 & 19.996 & 2.165 & -5.350 & -1.541 & 3.809 & 372.92 \\
\hline Acetone & 20.6 & 28.495 & -0.674 & 128.671 & 0.916 & 20.731 & 2.901 & -5.384 & -1.591 & 3.792 & 377.25 \\
\hline $\mathrm{MeOH}$ & 32.6 & 28.479 & -0.689 & 128.749 & 0.994 & 20.844 & 3.014 & -5.390 & -1.600 & 3.789 & 378.02 \\
\hline DMF & 36.7 & 28.476 & -0.693 & 128.766 & 1.011 & 20.868 & 3.037 & -5.391 & -1.602 & 3.788 & 376.87 \\
\hline DMSO & 46.6 & 28.471 & -0.698 & 128.792 & 1.037 & 20.902 & 3.072 & -5.393 & -1.605 & 3.787 & 377.09 \\
\hline $\mathrm{EtOH}$ & 22.4 & 28.487 & -0.681 & 128.707 & 0.952 & 20.785 & 2.954 & -5.387 & -1.596 & 3.790 & 377.61 \\
\hline $\mathrm{Et}_{2} \mathrm{O}$ & 4.3 & 28.644 & -0.525 & 128.165 & 0.410 & 19.549 & 1.719 & -5.334 & -1.518 & 3.816 & 370.85 \\
\hline
\end{tabular}


Table 5 Theoretical results of Compound 4 from DFT/PCM/B3LYP/6-31G(d)

\begin{tabular}{|c|c|c|c|c|c|c|c|c|c|c|c|c|c|}
\hline solvent & $\begin{array}{l}\text { Dielectric } \\
\text { constant }\end{array}$ & $\left({ }^{\circ}\right)$ & $\begin{array}{l}\text { dif } \\
\text { vacuo }\end{array}$ & $\theta 2\left(^{\circ}\right)$ & $\begin{array}{l}\text { dif } \\
\text { vacuo }\end{array}$ & $\theta 3\left(^{\circ}\right)$ & $\begin{array}{l}\text { dif } \\
\text { vacuo }\end{array}$ & $\begin{array}{l}\theta 4 \\
\left({ }^{\circ}\right)\end{array}$ & $\begin{array}{l}\text { dif } \\
\text { vacuo }\end{array}$ & $\begin{array}{l}\text { HOMO } \\
(\mathrm{eV})\end{array}$ & $\begin{array}{l}\text { LUMO } \\
(\mathrm{eV})\end{array}$ & $\begin{array}{l}\text { GAP } \\
(\mathrm{eV})\end{array}$ & $\begin{array}{l}\lambda_{\max } \\
(\mathrm{nm})\end{array}$ \\
\hline vacuo & --- & 30.078 & --- & 127.667 & --- & 12.712 & --- & 9.474 & --- & -4.683 & -1.149 & 3.534 & 393.65 \\
\hline Hexane & 1.9 & 30.014 & -0.064 & 127.830 & 0.163 & 14.249 & 1.537 & 8.860 & -0.614 & -4.753 & -1.247 & 3.506 & 401.24 \\
\hline Toluene & 2.4 & 29.964 & -0.114 & 127.915 & 0.248 & 14.664 & 1.952 & 8.630 & -0.844 & -4.778 & -1.281 & 3.496 & 403.61 \\
\hline THF & 7.6 & 29.653 & -0.425 & 128.239 & 0.572 & 15.202 & 2.489 & 7.750 & -1.723 & -4.864 & -1.405 & 3.459 & 413.14 \\
\hline Dioxane & 2.2 & 29.981 & -0.097 & 127.889 & 0.222 & 14.555 & 1.843 & 8.700 & -0.774 & -4.770 & -1.271 & 3.499 & 402.83 \\
\hline $\mathrm{ACN}$ & 37.5 & 29.447 & -0.631 & 128.437 & 0.770 & 15.027 & 2.315 & 7.241 & -2.233 & -4.908 & -1.470 & 3.438 & 418.38 \\
\hline $\mathrm{CHCl}_{3}$ & 4.8 & 29.768 & -0.310 & 128.129 & 0.462 & 15.157 & 2.445 & 8.041 & -1.433 & -4.837 & -1.365 & 3.471 & 410.03 \\
\hline DCM & 9.1 & 29.614 & -0.464 & 128.276 & 0.609 & 15.193 & 2.481 & 7.655 & -1.819 & -4.873 & -1.418 & 3.455 & 414.14 \\
\hline DCE & 10.4 & 29.590 & -0.488 & 128.298 & 0.631 & 15.182 & 2.470 & 7.596 & -1.878 & -4.878 & -1.425 & 3.452 & 414.76 \\
\hline $\begin{array}{l}\text { Ethyl } \\
\text { acetate }\end{array}$ & 6.0 & 29.704 & -0.374 & 128.190 & 0.523 & 15.196 & 2.483 & 7.878 & -1.596 & -4.852 & -1.388 & 3.464 & 411.79 \\
\hline Acetone & 20.6 & 29.492 & -0.586 & 128.393 & 0.726 & 15.094 & 2.381 & 7.354 & -2.120 & -4.899 & -1.456 & 3.442 & 417.26 \\
\hline $\mathrm{MeOH}$ & 32.6 & 29.453 & -0.625 & 128.431 & 0.764 & 15.037 & 2.325 & 7.256 & -2.218 & -4.907 & -1.468 & 3.438 & 418.24 \\
\hline DMF & 36.7 & 29.444 & -0.633 & 128.439 & 0.773 & 15.023 & 2.311 & 7.235 & -2.239 & -4.909 & -1.471 & 3.437 & 418.44 \\
\hline DMSO & 46.6 & 29.432 & -0.646 & 128.452 & 0.785 & 15.001 & 2.289 & 7.203 & -2.271 & -4.911 & -1.475 & 3.436 & 418.76 \\
\hline $\mathrm{EtOH}$ & 22.4 & 29.474 & -0.604 & 128.411 & 0.744 & 15.069 & 2.357 & 7.308 & -2.166 & -4.903 & -1.462 & 3.440 & 417.71 \\
\hline $\mathrm{Et}_{2} \mathrm{O}$ & 4.3 & 29.798 & -0.280 & 128.100 & 0.433 & 15.125 & 2.413 & 8.120 & -1.354 & -4.829 & -1.354 & 3.474 & 409.17 \\
\hline
\end{tabular}

As previously mentioned, it is important to know the influence of the solvent on the quinoline core without substituents, so we do not limit our explanation of the change in values only in relation with the twist angle of substituents $(\theta 1, \theta 2, \theta 3$ and $\theta 4)$. The dihedral angles are shown in Fig. 8. All the results presented by computational studies are summarized in Table 4 and Table 5 .

Theoretical results showed that for compounds $\mathbf{3}$ and $\mathbf{4}$, angle $\theta 1$, even in different solvents, does not present major changes. On the other hand, when we observe the dihedral angles between phenyl rings and quinoline base, it is possible to see that, when changing the solvent, torsions up to $3^{\circ}$ were observed in dihedral angles $\theta 2$ and $\theta 3$; when the dielectric constant is increased, the changes in $\theta 2$ and $\theta 3$ also increase, indicating a greater interaction between the solvent and the molecule. As for $\theta 4$ of $\mathbf{4}$, we can see variations up to $2.3^{\circ}$, with greater variations in those with higher dielectric constants.
The mobility that the molecule presents makes the structure favorable to the effect of the solvent type and thus hinders the correlation between theoretical and experimental values for maximum absorption length. However, we found a trend in the behavior of these molecules. Initially, with the data obtained theoretically, we observed a correlation between the dielectric constant of the solvent and the $\lambda_{\max }$. A first correlation was found between the dielectric constant and the experimental $\lambda_{\max }$ (Fig. 9), and a second correlation was found between the dielectric constant and the theoretical $\lambda_{\max }$ (Fig. 10). The value of $\mathrm{R}$ indicates a strong correlation between experimental and theoretical studies [34].

Figures 9 and 10 show strong correlation between $\lambda_{\max }$ and dielectric constant. The tendency is to increase the dielectric constant, shifting the $\lambda_{\max }$ batochromically. The errors occur because the absorption phenomenon depends on other factors that cause changes in the electronic structure of the molecule such as viscosity,
Fig. 8 Compound $\mathbf{3}$ (a) and $\mathbf{4}$ (b)

and the dihedral angles

considered for computations<smiles>c1ccc(-c2cc(-c3ccccc3)c3c[14cH]ccc3n2)cc1</smiles>

b<smiles>CN(C)c1ccc(-c2cc(-c3ccccc3)c3cc(N)ccc3n2)cc1</smiles> 
a

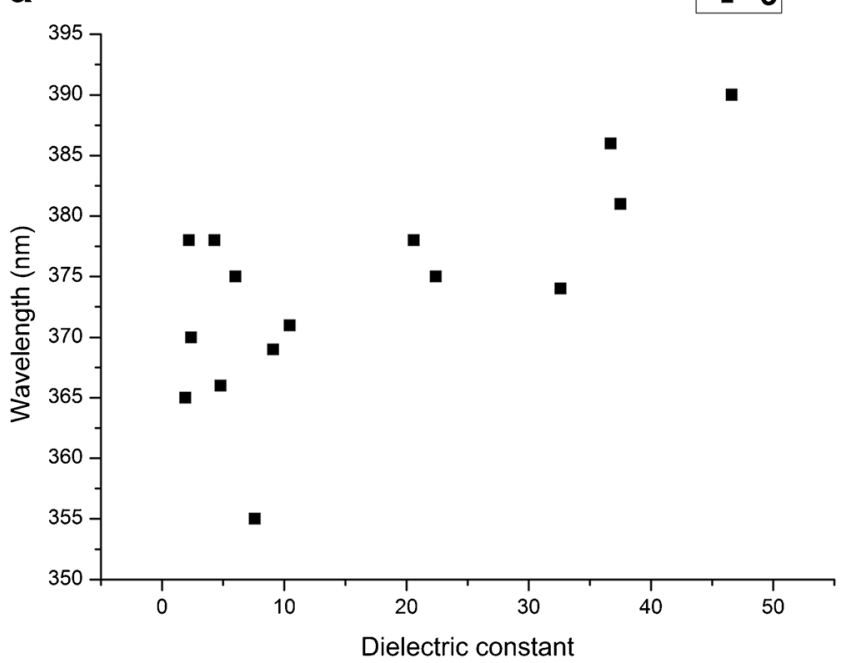

b

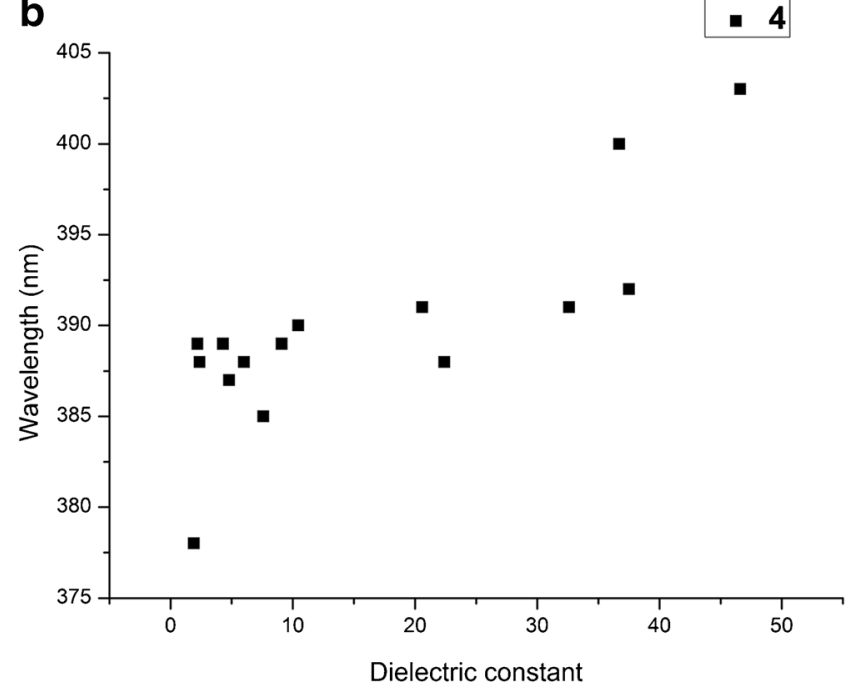

Fig. 9 Experimental results. a Compound 3, correlation between wavelength and dielectric constant $R=0.70$. b Compound $\mathbf{4} R=0.80$

polarity, and, therefore, solubility [27]. Theoretical studies minimize these errors relative to dielectric constant. In these studies, the interaction of the electron cloud between the solvent and the compound is considered and the effect of viscosity and others previously mentioned is not considered. But even so, what probably plays a major role in the geometry of the molecule, in the solvatochromism, is the electrostatic and orbital interactions with the solvent.

Another observation regarding the theoretical correlation is that reaching the high values of dielectric constant seems to be saturation, and wavelength does not follow a linear increase.

Further investigations of this class of D-A-D systems, as well as the synthesis and modification of groups to know photovoltaic properties in optoelectronic devices, will be studied and will be reported in future publications.

a



\section{Conclusion}

The solvatochromic effect and photophysical properties of quinoline derivatives in various solvents were studied to know their relation with each substituent in the structure. Among the substituents, we highlighted the dimethylamine group. In addition, it is possible to observe the highlighted effect on the absorption bathochromic shift and fluorescence displayed by the compounds having amine group at position 6 of the quinoline core. This demonstrates the importance of inserting the phenyl groups, but also confirms the key effect of the amino group at position 6 of the quinoline backbone.

In theoretical calculations, both effects of solvation and electrostatic factors were taken into consideration. Thus, molecules 3 and $\mathbf{4}$ were further studied by the properties highlighted based on an earlier study. A correlation between theoretical and experimental maximum absorption length and the

b



Fig. 10 Theoretical results. a Compound 3, correlation between wavelength and dielectric constant $R=0.76$. b Compound $4 R=0.80$ 
dielectric constant was observed. In general, the $\lambda_{\max }$ can be predicted with good accuracy. It is difficult to be precise as to when the molecule is more flexible because the structure is more difficult to be predicted, therefore the geometry of the excited state can greatly differ from the ground state. The solvatochromic effect was studied in the two molecules, being more pronounced in molecule 4, a D-A-D molecule type. All results obtained in this study are important for quantum chemistry practical applications in the design of functional dyes.

Ackowledgements The authors would like to thank Fundação de Amparo à Pesquisa do Estado de São Paulo (FAPESP) (Procs. 2013/08697-0, 2012/24199-8, 2012/21983-0, 2014/20410-1, 2015/00615-0 and 2016/01599-1), Conselho Nacional de Desenvolvimento Científico e Tecnológico (CNPq) (Proc. 302,753/2015-0) and PróReitoria de Pesquisa (PROPe-UNESP) for their financial support. We would also like to thank CBMM - Companhia Brasileira de Mineralogia e Mineração for the $\mathrm{NbCl}_{5}$ samples. This research was also supported by resources supplied by the Center for Scientific Computing (NCC/GridUNESP) of the São Paulo State University (UNESP).

\section{References}

1. Balijapalli U, Iyer SK (2015) Synthesis and optical properties of a series of green-light-emitting 2-(4-Phenylquinolin-2-yl) phenolBF2 complexes (Boroquinols). Eur J Org Chem 23:5089-5098

2. Michael JP (1997) Quinoline, quinazoline and acridone alkaloids. Nat Prod Rep 14(6):605-618

3. Markees DG, Dewey VC, Kidder GW (1970) Antiprotozoal 4aryloxy-2-aminoquinolines and related compounds. J Med Chem 13(2):324-326

4. Dumouchel S, Mongin F, Trécourt F, Quéguiner G (2003) Tributylmagnesium ate complex-mediated bromine-magnesium exchange of bromoquinolines: a convenient access to functionalized quinolines. Tetrahedron Lett 44(10):2033-2035

5. Goel A, Kumar V, Singh SP, Sharma A, Prakash S, Singh C, Anand RS (2012) Non-aggregating Solvatochromic bipolar benzo-[f]quinolines and benzo-[a]-acridines for organic electronics. J Mater Chem 22(30):14880-14888

6. Zhang X, Kale DM, Jenekhe SA (2002) Electroluminescence of multicomponent conjugated polymers. 2. Photophysics and enhancement of electroluminescence from blends of polyquinolines. Macromolecules 35(2):382-393

7. Lin LY, Chen YH, Huang ZY, Lin HW, Chou SH, Lin F, Chen CW, Liu YH, Wong KT (2011) A low-energy-gap organic dye for highperformance small-molecule organic solar cells. J Am Chem Soc 133(40):15822-15825

8. Choi HJ, Choi HB, Paek SH, Song KH, Kang MS, Ko JJ (2010) Novel organic sensitizers with a quinoline unit for efficient dyesensitized solar cells. Bull Kor Chem Soc 31(1):125-132

9. Havinga EE, ten Hoeve W, Wynberg H (1992) A new class of small band gap organic polymer conductors. Polym Bull 29(1-2):119-126

10. Kumar V, Gohain M, Van Tonder JH, Ponra S, Bezuindenhoudt BCB, Ntwaeaborwa OM, Swart HC (2015) Synthesis of quinoline based heterocyclic compounds for blue lighting application. Opt Mater 50:275-281

11. Yune JH, Karatchevtseva I, Evans PJ, Wagner K, Griffith MJ, Officer D, Triani G (2015) A versatile binder-free $\mathrm{TiO}_{2}$ paste for dye-sensitized solar cells. RSC Adv 5(37):29513-29523

12. dos Santos GC, Bartolomeu AA, Ximenes VF, da Silva-Filho LC (2016) Facile synthesis and Photophysical characterization of new Quinoline dyes. J Fluoresc. doi:10.1007/s10895-016-1954-5

13. Fery-Forgues S, Lavabre D (1999) Are fluorescence quantum yields so tricky to measure? A demonstration using familiar stationery products. J Chem Educ 76(9):1260

14. Frisch MJ, Trucks GW, Schlegel HB, Scuseria GE, Robb MA, Cheeseman, JR, ..., Nakatsuji H (2009) Gaussian 09, revision A. 1. Gaussian Inc., Wallingford

15. Becke AD (1993) Density-functional thermochemistry. III The role of exact exchange J Chem Phys 98(7):5648-5652

16. Ditchfield RHWJ, Hehre WJ, Pople JA (1971) Self-consistent molecular-orbital methods. IX An extended Gaussian-type basis for molecular-orbital studies of organic molecules. J Chem Phys 54(2):724-728

17. Miertuš S, Scrocco E, Tomasi J (1981) Electrostatic interaction of a solute with a continuum. A direct utilizaion of $\mathrm{AB}$ initio molecular potentials for the prevision of solvent effects. Chem Phys 55(1): 117-129

18. Mennucci B (2012) Polarizable continuum model. Wiley Interdiscip Rev: Comput Mol Sc 2(3):386-404

19. Akbar R, Baral M, Kanungo BK (2015) Experimental and DFT assessment on the development of Tris (methoxymethyl)-5-oxine. J Chem Eng 60(11):3236-3245

20. Ebenso EE, Kabanda MM, Arslan T, Saracoglu M, Kandemirli F, Murulana LC, Quraishi MA (2012) Quantum chemical investigations on quinoline derivatives as effective corrosion inhibitors for mild steel in acidic medium. Int J Electrochem Sci 7:5643-5676

21. Kumru M, Küçük V, Kocademir M (2012) Determination of structural and vibrational properties of 6-quinolinecarboxaldehyde using FT-IR, FT-Raman and dispersive-Raman experimental techniques and theoretical HF and DFT (B3LYP) methods. Spectrochim Acta A 96:242-251

22. Fazal E, Jasinski JP, Anderson BJ, Kaur M, Nagarajan S, Sudha BS (2015) Synthesis, crystal and molecular structure studies and DFT calculations of phenyl quinoline-2-carboxylate and 2methoxyphenyl quinoline-2-carboxylate; two new quinoline-2 carboxylic derivatives. Crystals 5(1):100-115

23. Stefanou V, Matiadis D, Melagraki G, Afantitis A, Athanasellis G, Igglessi-Markopoulou O, Markopoulos J (2011) Functionalized 4hydroxy coumarins: novel synthesis, crystal structure and DFT calculations. Molecules 16(1):384-402

24. Mirjafary Z, Saidian H, Sahandi M, Shojaei L (2014) Efficient synthesis of novel pyranoquinoline derivatives from simple acetanilide derivatives: experimental and theoretical study of their physicochemical properties using DFT calculations. J Brazil Chem Soc 25(7):1253-1260

25. Pavia DL, Lampman GM, Kriz GS (2001) Introduction to spectroscopy: a guide for students of organic chemistry, 3rd ed. Thomson Learning Inc., Bellingham

26. Nedeltchev AK, Han H, Bhowmik PK (2010) Photoactive amorphous molecular materials based on quinoline amines and their synthesis by Friedländer condensation reaction. Tetrahedron 66(48):9319-9326

27. Lakowicz JR (2006) Principles of fluorescence spectroscopy. Springer, New York

28. Park KK, Park JW, Hamilton AD (2007) Solvent and pH effects on the fluorescence of 7-(Dimethylamino)-2-Fluorenesulfonate. J Fluoresc 17(4):361-369

29. Chang DW, Ko SJ, Kim JY, Dai L, Baek JB (2012) Multifunctional quinoxaline containing small molecules with multiple electron- 
donating moieties: Solvatochromic and optoelectronic properties. Synthetic Met 162(13):1169-1176

30. Nazim M, Ameen S, Seo HK, Shin HS (2015) Effective DAD type chromophore of fumaronitrile-core and terminal alkylated bithiophene for solution-processed small molecule organic solar cells. Sci Rep 5:11143

31. Guillaumont D, Nakamura S (2000) Calculation of the absorption wavelength of dyes using time-dependent density-functional theory (TD-DFT). Dyes Pigments 46(2):85-92

32. Burrows PE, Shen Z, Bulovic V, McCarty DM, Forrest SR, Cronin JA, Thompson ME (1996) Relationship between electroluminescence and current transport in organic heterojunction light-emitting devices. J Appl Phys 79(10): 7991-8006

33. Gao N, Cheng C, Yu C, Hao E, Wang S, Wang J, Wei Y, Mu X, Jiao L (2014) Facile synthesis of highly fluorescent $\mathrm{BF}_{2}$ complexes bearing isoindolin-1-one ligand. Dalton Trans 43(19):7121-7127

34. Mukaka MM (2012) A guide to appropriate use of correlation coefficient in medical research. Malawi Med J 24(3):69-71 